\title{
SIMULAÇÃO COMPUTACIONAL DAS PANELAS DE ACIARIA DA SIDERÚRGICA SINOBRAS S.A.
}

\author{
Márcio Corrêa de Carvalho' \\ Daniel Rodrigues Oliveira ${ }^{2}$ \\ Gerson Ceslau Rusky ${ }^{3}$ \\ Bruno Corrêa Pinheiro ${ }^{4}$ \\ José António da Silva Souza ${ }^{5}$ \\ Eduardo Magalhães Braga ${ }^{6}$
}

\section{Resumo}

O objetivo do presente trabalho consiste em estudar o comportamento térmico das panelas durante as etapas do ciclo operacional utilizando modelos de transferência de calor e simulação computacional. A partir dos resultados do estudo se procurou fazer modificações com o intuito de diminuir as perdas de energia calorífica durante as etapas do processo produtivo. Através da modelagem matemática, medições na planta e simulações computacionais foram determinadas as quedas de temperatura e perdas de calor das panelas. A partir daí foram propostas mudanças operacionais e físicas que após testes práticos e ou simulações computacionais se mostraram eficientes para a diminuição das perdas caloríficas e menor consumo de energia elétrica no forno-panela.

Palavras-chave: Panela de aciaria; Simulação computacional; Controle da temperatura em panelas; Ciclo operacional de panelas.

\section{COMPUTATIONAL SIMULATION OF LADLES OF STEELMAKING SINOBRAS S.A.}

\begin{abstract}
The aim of this work consists in studing the thermal behavior of ladles during steps of the operating cycle using heat transfer equations and computational simulation. From the study results sought to make improvements in order to reduce the loss of heat energy during steps of the production process. Through mathematical modeling, measurements in the plant and computational simulations were determined the temperature drops and heat losses. Therefore were proposed operational and physical changes that after practice tests and or computational simulations proved to be efficient for the reduction of heat loss and lower consumption in the ladle furnace.
\end{abstract}

Keywords: Ladle; Computational simulation; Temperature control on ladles; Operational cycle of ladles.

\section{INTRODUÇÃO}

As panelas de aço utilizadas em aciaria para o transporte e metalurgia secundária precisam trabalhar em temperaturas adequadas para que não haja grandes perdas de energia calorífica no aço líquido e para que os refratários não sofram choques térmicos. Um controle de temperatura no ciclo operacional das panelas é de primordial importância para o acerto de temperatura do aço líquido com um menor consumo de energia elétrica no

\footnotetext{
'Engenheiro Químico, Doutorando, Programa de Pós-Graduação em Engenharia de Recursos Naturais da Amazônia, Universidade Federal do Pará - UFPA, Belém, PA, Brasil. E-mail: corream@ufpa.br

${ }^{2}$ Graduando da Faculdade de Engenharia de Materiais, Universidade Federal do Pará - UFPA, estagiário, Sinobras, Marabá, PA, Brasil.

E-mail: danielsou12@hotmail

${ }^{3}$ Engenheiro Metalúrgico, Gerente Executivo, Sinobras, Marabá, PA, Brasil: gerson.rusky@sinobras.com.br

${ }^{4}$ Engenheiro Metalúrgico, Engenheiro de Processos, Sinobras, Marabá, PA, Brasil: E-mail: bruno.pinheiro@sinobras.com.br

${ }^{5}$ Engenheiro Químico, Professor Dr., Programa de Pós-Graduação em Engenharia de Recursos Naturais da Amazônia,

Universidade Federal do Pará - UFPA, Belém, PA, Brasil.E-mail: jass@ufpa.br

${ }^{6}$ Engenheiro Mecânico, Professor Dr., Programa de Pós-Graduação em Engenharia de Recursos Naturais da Amazônia,

Universidade Federal do Pará - UFPA, Belém, PA, Brasil. E-mail: edbraga@ufpa.br
} 
forno panela e também para se diminuir as perdas caloríficas pelas panelas. As maiores perdas de calor se devem as etapas de panela vazia. Estas etapas consistem na limpeza, manutenção, adição de areia de vedação e tempo de espera até o vazamento.

A partir do uso de modelos de transferência de calor e simulação computacional se pode obter a queda de temperatura das panelas em diferentes condições de serviço. Segundo o trabalho de Lopes [I], ele mostra que as perdas térmicas podem ser divididas em perdas térmicas com a panela cheia (perdas térmicas do aço líquido) e perdas térmicas através da panela vazia (perdas térmicas através dos refratários) e demonstra também as modelagens matemáticas sob estas condições. Segundo o trabalho de Minion e Leckie [2] essas perdas podem ser minimizadas com uma boa prática de panela quente que consiste em: Manter uma alta temperatura do refratário da panela no vazamento, isolar termicamente o refratário e utilização de tampa.

Segundo o trabalho de Ferreira [3] as perdas térmicas que acontecem com a panela vazia são muito elevadas devido a grande quantidade de energia contida nas camadas refratárias e às elevadas temperaturas da face quente.

O objetivo deste trabalho é a de se realizar um estudo das condições térmicas das panelas da aciaria Sinobras através de coleta de dados na área, modelagem matemática e simulação computacional das panelas em operação. Após, determinar as quedas de temperatura e perdas caloríficas. Através dos resultados foram propostas mudanças físicas e operacionais para a diminuição das perdas caloríficas.

\section{MATERIAIS E MÉTODOS}

\section{I Determinações das Quedas de Temperatura das Panelas}

Para se conhecer o comportamento térmico das panelas quando vazias se realizou medições de temperatura da carcaça e do interior. Estas foram realizadas nas seguintes etapas do processo:

- Panela antes da limpeza;

- Panela após limpeza;

- Panela após adição de areia de vedação e;

- Panela antes do vazamento.

Para as medições foi necessária a utilização de um pirômetro infra-vermelho com faixa de medições de $50^{\circ} \mathrm{C}-2.200^{\circ} \mathrm{C}$. Os pontos de medida na carcaça foram marcados em todas as panelas para padronização dos pontos de medida. A Figura I mostra os pontos de retirada de temperatura.
A partir dos valores encontrados foi montado um banco de dados em planilha de Excel como visto em parte na Tabela I. O acompanhamento foi feito com e sem a utilização da tampa durante o ciclo operacional para se efetuar posteriores comparações.

\subsection{Determinação das Quedas de Temperatura do Aço Líquido Durante o Vazamento}

Analisou-se a diminuição de temperatura do aço líquido existente entre o vazamento e a chegada da panela no forno-panela. O objetivo desta análise foi determinar se havia uma relação entre a temperatura dos refratários das panelas antes do vazamento com a queda de temperatura do aço líquido durante o tempo já mencionado.

Para se determinar as temperaturas foram utilizados os valores inseridos no Sistema de Gestão do processo de Produção da empresa e a partir daí montada uma planilha de dados em Excel.

\subsection{Modelamento Matemático das Panelas}

Foram feitos algumas considerações que serão as condições de contorno. As transferências de calor consideradas foram:

- Condução de calor pelos refratários e chapa metálica;

- Convecção e radiação pela chapa metálica em contato com o ambiente;

- Convecção, radiação e reirradiação pelo interior da panela através da face quente;

- Foi desconsiderada a influência da camada de escória "coating" que se forma pelas paredes e fundo da panela.

A transferência de calor pela panela obedeceu a geometria cilíndrica nas paredes laterais e retangulares no fundo. Foi considerado que as taxas de transferência de calor eram unidimensionais e em regime estacionário, como mostrado em Gupta et al. [4]. Segundo Fredman [5] a aproximação unidimensional tem sido um método bastante aceito entre os pesquisadores. As equações diferenciais simplificadas para geometria retangular e cilíndrica de acordo com Incropera [6] e Seshadri [7] são mostradas respectivamente nas Equações I e 2:

$$
\begin{aligned}
& \frac{\mathrm{d}}{\mathrm{dx}}\left(\mathrm{k} \frac{\mathrm{dT}}{\mathrm{dx}}\right)=0 \\
& \frac{\mathrm{I}}{r} \frac{d}{d r}\left(k r \frac{d T}{d r}\right)=0
\end{aligned}
$$

As equações que descrevem as taxas de transferências de calor foram de acordo com as teorias mostradas em Incropera [6], Seshadri [7] e Suzaki et al. [8] para paredes compostas. Estas foram: 

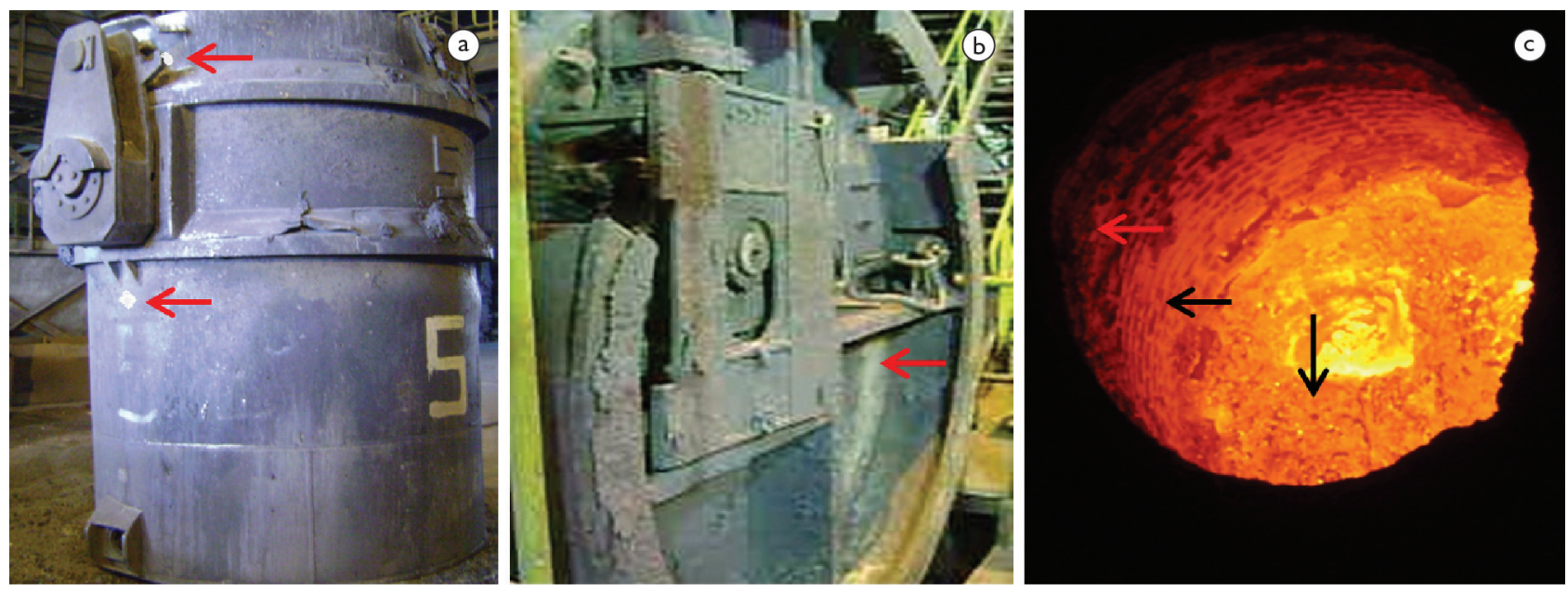

Figura I. Fotos de uma panela mostrando os locais de retirada de temperatura.

Tabela I. Levantamento das temperaturas das panelas durante ciclo operacional (exemplo)

\begin{tabular}{|c|c|c|c|c|c|c|c|c|c|c|c|}
\hline Dia & Corrida & Pan. & Horário & Etapa & $\begin{array}{c}\text { LE ext } \\
\left({ }^{\circ} \mathrm{C}\right)\end{array}$ & $\begin{array}{c}\text { LE int } \\
\left({ }^{\circ} \mathrm{C}\right)\end{array}$ & $\begin{array}{l}\text { Centro } \\
\text { ext }\left({ }^{\circ} \mathrm{C}\right) \\
\end{array}$ & $\begin{array}{l}\text { Centro } \\
\text { int }\left({ }^{\circ} \mathrm{C}\right) \\
\end{array}$ & $\begin{array}{c}\text { Fundo } \\
\operatorname{ext}\left({ }^{\circ} \mathrm{C}\right)\end{array}$ & $\begin{array}{l}\text { Fundo } \\
\text { int }\left({ }^{\circ} \mathrm{C}\right)\end{array}$ & Cond. \\
\hline $20 / 11 / 12$ & 126939 & 4 & $16 \mathrm{~h} / 3$ & antes da limpeza & 327 & 980 & 350 & 1.030 & 350 & 1.220 & ST \\
\hline $20 / 11 / 12$ & 126939 & 4 & $16 \mathrm{~h} 39$ & depois da limpeza & 320 & 900 & 345 & 945 & 300 & 1.040 & ST \\
\hline $20 / 11 / 12$ & 126939 & 4 & $16 \mathrm{~h} 39$ & após ad. Areia & 317 & 750 & & 826 & & & ST \\
\hline $20 / 11 / 12$ & 126939 & 4 & $16 \mathrm{~h} 56$ & antes do vazamento & 316 & 726 & & & & & ST \\
\hline
\end{tabular}

Transferência de calor por condução pela parede lateral (Equação 3):

$$
Q_{\text {parede }}=\frac{T_{f q}-T_{c h}}{\frac{\ln \frac{R I}{R i}}{2 \pi L K t}+\frac{\ln \frac{R 2}{R l}}{2 \pi L K p}+\frac{\ln \frac{R 3}{R 2}}{2 \pi L K c}}
$$

Transferência de calor por condução e convecção pelo fundo da panela (Equação 4):

$$
Q_{\text {frndo }}=\frac{T_{\infty, i}-T_{\infty, e}}{\frac{1}{h_{r-a r} * A f}+\frac{L_{t}}{K t * A f}+\frac{L_{p}}{K p * A f}+\frac{L_{c h}}{K c h * A f}+\frac{1}{h_{c h-a r} * A f}}
$$

Transferência de calor por convecção e radiação pela chapa metálica (Equações 5 e 6):

Convecção:

$$
Q c h_{c}=h_{c h-a r} \cdot\left(T_{c h}-T_{\infty, e}\right) A_{c h}
$$

Radiação:

$$
Q_{c h}=\frac{A_{c h} \cdot \sigma \cdot\left(T_{c h}{ }^{4}-T_{\infty, e}{ }^{4}\right)}{\left(\frac{1}{\varepsilon_{c h}}+\frac{1}{\varepsilon_{a r}}-1\right)}
$$

Transferência de calor pela face quente (Equações 7-13):
Convecção:

$Q f q_{c}=h_{r-a r} \cdot\left(T_{f q-} T_{\infty, i}\right) \cdot A_{\text {int }}$

Radiação e irradiação:

$$
\begin{aligned}
& Q c h_{c}=h_{c h-a r} \cdot\left(T_{c h}-T_{\infty, e}\right) A_{c h} \\
& h_{r-a r}=\frac{N u \cdot K a r}{L}+\frac{N u \cdot K a r}{\varnothing_{\text {int }} \text { da panela }} \\
& Q f q_{r}=\frac{A_{f} \cdot \sigma \cdot\left(T_{f q}^{4}-T_{\infty, e}{ }^{4}\right)}{\frac{1-\varepsilon_{r}}{\varepsilon_{r}}+\frac{1}{F_{12}}+\left(\frac{1}{F_{1 R}}-\frac{1}{F_{2 R}}\right)}+\mathrm{I}-\frac{\varepsilon_{a r}}{\varepsilon_{a r}} \\
& Q f q_{r^{\prime}}=A_{f} \cdot \sigma \cdot \varepsilon_{r} \cdot\left(T_{f q}{ }^{4}-T_{\infty, e}{ }^{4}\right) \\
& Q f q_{r^{\prime \prime}}=A_{\text {int }} \cdot \sigma \cdot \varepsilon_{r} \cdot\left(T_{f q}{ }^{4}-T_{\infty, e}{ }^{4}\right)
\end{aligned}
$$

$Q$ radiação $=Q f q_{r}+Q f q_{r^{\prime \prime}}-Q f q_{r^{\prime}}$

Sendo:

- $T_{f q}=$ Temperatura na face quente $\left({ }^{\circ} \mathrm{C}\right)$

- $T_{c h}=$ Temperatura na chapa metálica $\left({ }^{\circ} \mathrm{C}\right)$

- $R i$ = Raio interno da panela $(\mathrm{m})$

- $R I=$ Raio até a face fria do tij. de trabalho $(\mathrm{m})$ 
- $R 2$ = Raio interno da carcaça metálica $(\mathrm{m})$

- $R 3$ = Raio externo da carcaça metálica $(\mathrm{m})$

- $K t=$ Cond. térmica do tijolo de trabalho-Dolmag $100\left(\mathrm{~W} / \mathrm{m}^{\circ} \mathrm{C}\right)$

- $K p=$ Condutividade térmica do tijolo permanente-Alukor70 $\left(\mathrm{W} / \mathrm{m}^{\circ} \mathrm{C}\right)$

- $K c=$ Condutividade térmica da carcaça metálica-aço estrutural $\left(\mathrm{W} / \mathrm{m}^{\circ} \mathrm{C}\right)$

- $L_{t}=$ Espessura do ref. de trabalho $(\mathrm{m})$

- $L_{p}=$ Espessura do ref. permanente $(\mathrm{m})$

- $L_{c h}=$ Espessura da carcaça metálica $(\mathrm{m})$

- $h_{c h-a r}=$ Coeficiente de convecção chapa- ar ambiente $\left(6,5 \mathrm{~W} / \mathrm{m}^{2} \mathrm{~K}\right)$

- $T_{\infty, \mathrm{e}}=$ Temp. ambiente externa a panela $\left({ }^{\circ} \mathrm{C}\right)$

- $A_{c h}=$ Área efetiva da carcaça $\left(\mathrm{m}^{2}\right)$

- $\sigma=$ Constante de Stefan-Boltzman

- $\varepsilon_{c h}=$ Emissividade da chapa $(0,80)$

- $\varepsilon_{a r}=$ Emissividade da vizinhança (ambiente=I)

- $h_{r-a r}=$ Coeficiente de convecção entre o refratário e ar na panela $\left(5,749 \mathrm{~W} / \mathrm{m}^{2} \mathrm{~K}\right)$

- $T_{\infty, i}=$ Temp. ambiente dentro da panela $\left({ }^{\circ} \mathrm{C}\right)$

- Aint = Área int. efetiva da face quente $\left(\mathrm{m}^{2}\right)$

- $\mathrm{Nu}=$ Número de Nusselt $(135,8)$

- Kar = Condutividade térmica do ar dentro da panela $(0,0909 \mathrm{~W} / \mathrm{mK})$

- $L=$ Altura efetiva da face quente (m)

- Øint da panela = Diâmetro interno da panela $(\mathrm{I}, 829 \mathrm{~m})$

- $Q f q_{r}=$ Taxa de transferência de calor pelo fundo com reirradiação(W)

- $Q f q_{r^{\prime}}=$ Taxa de transferência de calor pelo fundo desconsiderando a reirradiação pelas paredes (W)

- $Q f q_{r "}=$ Taxa de transferência de calor pelas paredes laterais por radiação.

- $A_{f}=$ Área do fundo da panela $\left(\mathrm{m}^{2}\right)$

- $F_{12}=$ Fator de vista fundo-ambiente

- $F_{I R}=$ Fator de vista fundo-lateral

- $F_{2 R}=$ Fator de vista lateral-ambiente

\subsection{Mudanças Propostas}

Segundo Minion [2] et al. e Andrade [9] et al. apud Lopes [I] para se ter a conservação de energia da panela é necessário que ela trabalhe o maior tempo possível. Foram propostas mudanças para se otimizar o processo, que foram posteriormente testadas. A primeira ideia foi mudar a prática da logística das panelas: As panelas vazias que necessitassem ficar em espera pelo vazamento permaneceriam tampadas logo após a limpeza e estas só deveriam ser destampadas e colocadas no carro de movimentação 10 minutos antes de realizar o vazamento. A segunda ideia foi o uso do FP para aproveitar o calor irradiado pela mesma. Para isto a panela vazia deveria ser colocado no carro e debaixo da abobada com os eletrodos abaixados,

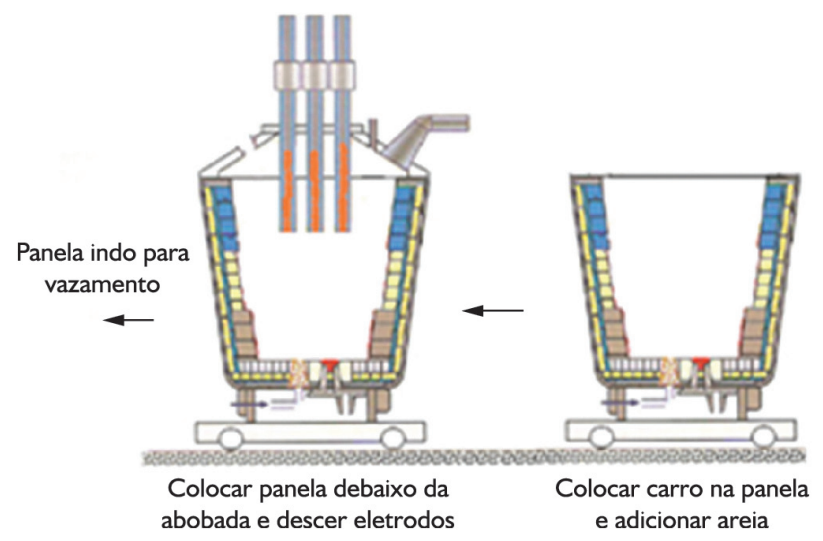

Figura 2. Esquema da mudança operacional.

fechando-se o damper. A mudança física foi a colocação de material isolante térmico nas paredes laterais das panelas para diminuir as perdas de energia pelos refratários. A Figura 2 mostra um esquema da mudança operacional.

\subsection{Desenvolvimento das Simulações Computacionais}

As discretizações e soluções foram feitas no programa Ansys Workbench vl I para a panela com tampa e sem tampa, com todos os seus refratários e também com material isolante a fim de se simular os efeitos de colocação de material isolante. Foram simuladas condições de aquecimento e resfriamento de acordo com os cálculos obtidos nos modelos matemáticos e dados recolhidos na planta. As discretizações da panela completa sem tampa e com tampa foram feitas utilizando respectivamente uma malha hexaédrica refinada de 162.924 e 138.417 nós e 156.659 e 123.323 elementos. As discretizações para as simulações de resfriamento levaram em conta somente - refratário de trabalho e o método utilizado foi o do tipo tetraédrico com alta relevância e com 1.460 .388 nós e 606.617 elementos. A Figura 3 mostra a malha para a panela sem tampa.

As propriedades termofísicas dos materiais foram fornecidas pelos fabricantes e estes foram inseridos no "data table" na etapa de pré-processamento do programa para as simulações.

\section{RESULTADOS E DISCUSSÕES}

\section{I Medidas de Temperatura}

Os resultados das medidas de temperatura foram colocados em uma planilha que é apresentada na Tabela I apenas em parte. Nesta tabela foram incluídas a data, o número da panela, o horário de medida, as temperaturas nos diversos pontos e a condição em que a panela se encontrava: 
A partir dos dados da planilha foram calculados os valores de taxas de queda de temperatura mostrados na Figura 4. Levando em consideração as quedas de temperatura na linha de escória (LE) durante o tempo em que a panela permanece em espera até a adição de areia de vedação constatou-se que para as panelas que permaneceram destampadas durante este período tiveram taxas

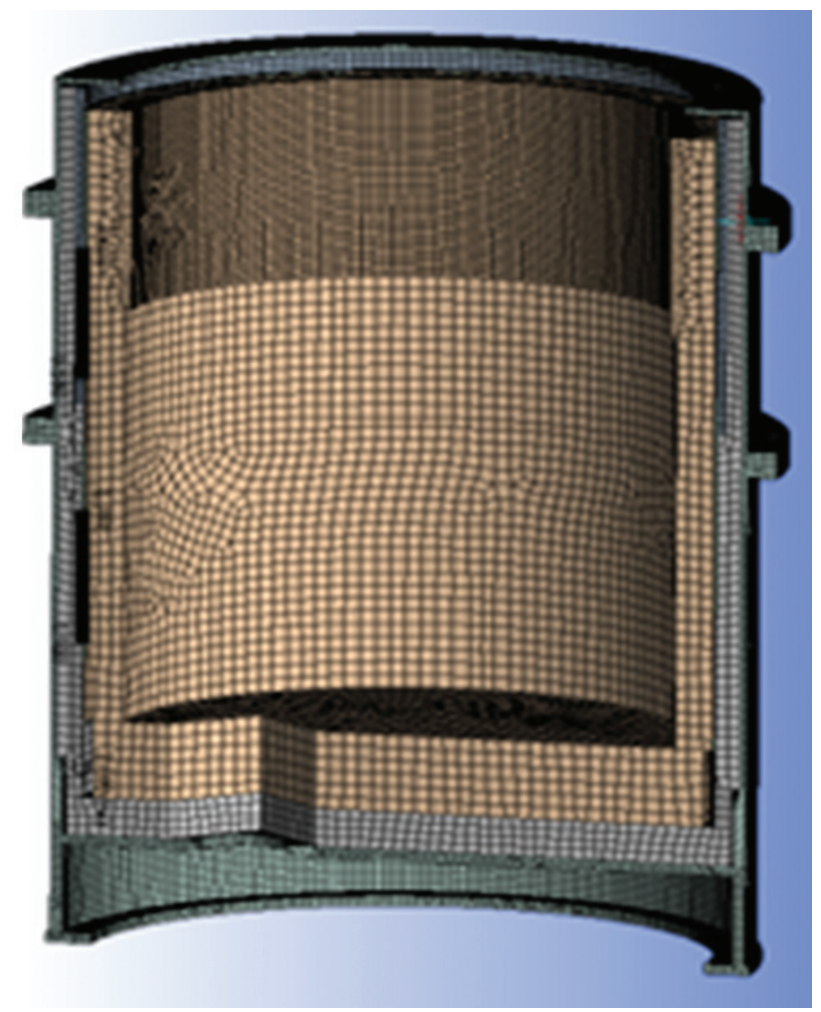

Figura 3. Exemplo de malha computacional gerada para panela sem tampa. de queda de temperatura variando entre $4,24^{\circ} \mathrm{C} / \mathrm{min}$ e $8,07^{\circ} \mathrm{C} / \mathrm{min}$. Já as que permaneceram tampadas tiveram taxas de queda de temperatura variando entre $0,68^{\circ} \mathrm{C} / \mathrm{min}$ e $5^{\circ} \mathrm{C} / \mathrm{min}$.

Para o período de tempo entre a adição de areia de vedação e o vazamento as panelas apresentaram os resultados de taxa de queda de temperatura vistos na Figura 5, para as condições: em que a panela permaneceu destampada durante todas as etapas, as que permaneceram tampadas e as que foram colocadas abaixo da abóbada do forno-panela:

Observa-se pelo gráfico da Figura 5 que as taxas das panelas que permaneceram destampadas foram maiores que nas demais condições e que o uso da abobada fez diminuir sensivelmente as taxas.

\subsection{Queda de Temperatura do Aço Líquido}

Foi feito um estudo das relações existentes entre a temperatura interna da panela antes do vazamento e a queda de temperatura do aço líquido entre o vazamento e a chegada da panela no forno-panela. A Figura 6 mostra esta relação.

Verificou-se a existência de uma relação entre a temperatura da linha de escória antes do vazamento e a queda de temperatura que acontece no aço líquido já descrito.

gráfico mostra que à medida que a temperatura da linha de escória na hora do vazamento é maior, há uma tendência de uma menor queda de temperatura sofrida no aço líquido e vice-versa.

\subsection{Simulações Computacionais}

Com os valores médios de fluxo de calor calculados a partir das temperaturas encontradas adicionados nos

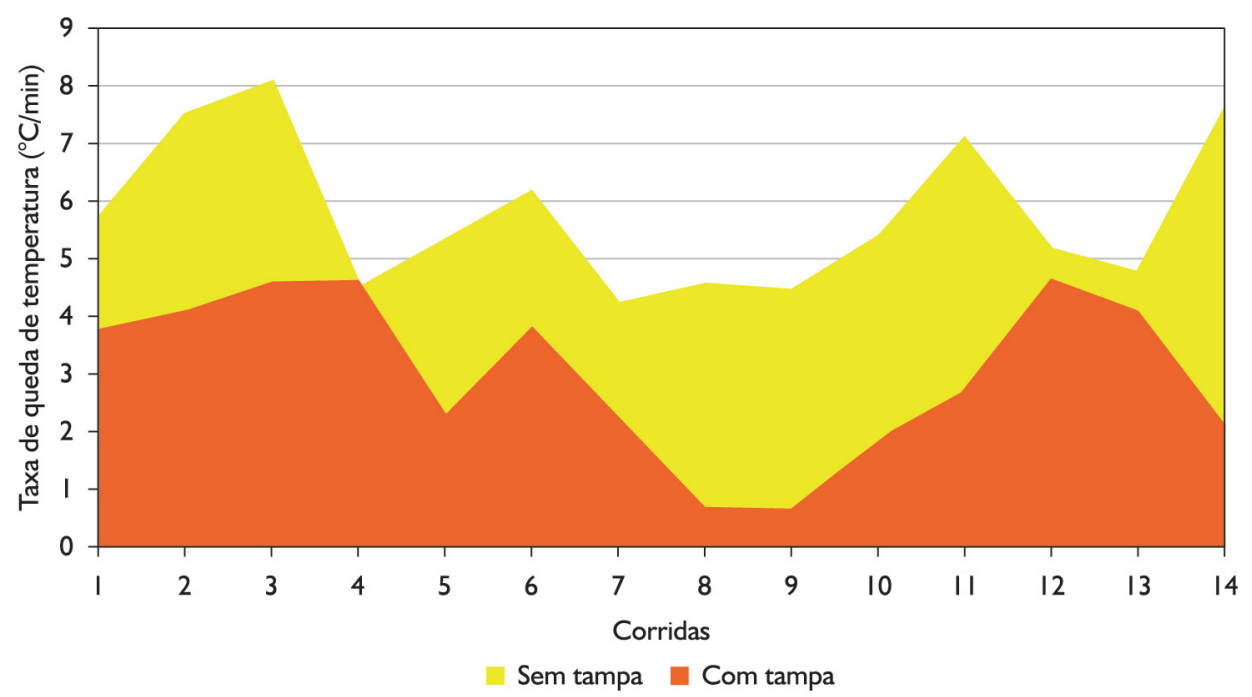

Figura 4. Taxas de queda de temperatura durante as corridas no período entre o término da limpeza até a adição de areia de vedação para panelas tampadas e destampadas. 


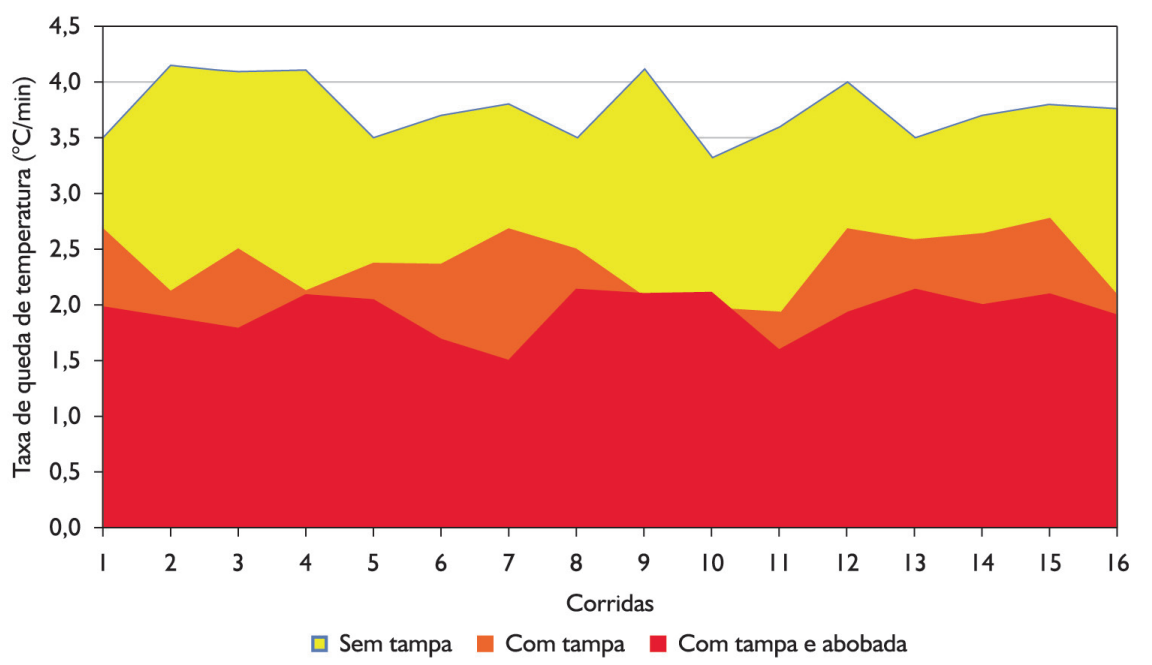

Figura 5. Taxas de queda de temperatura com as corridas entre a adição de areia e o vazamento para as condições de panelas destampadas, tampadas e as que foram colocadas sob a abóbada.

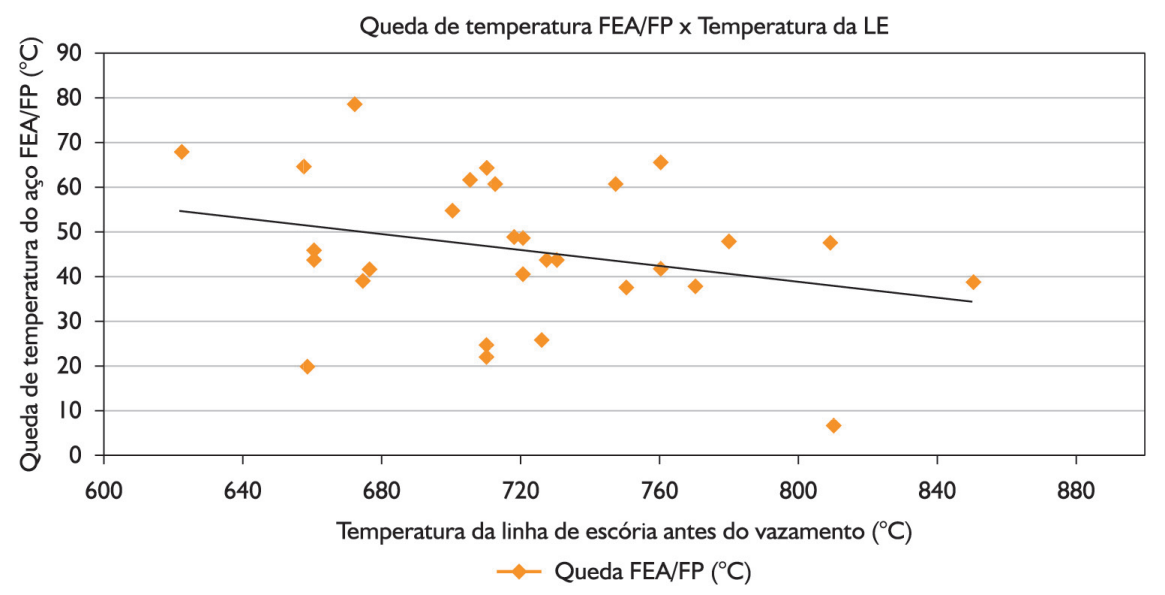

Figura 6. Relação entre queda de temperatura entre FEA e Forno Panela e a temperatura da linha escória antes do vazamento.

parâmetros das simulações os resultados das simulações de resfriamento mostraram quais seriam os resultados de perfis de temperatura na linha de escória (direção $\mathrm{x}$ ) esperados para as panelas durante enquanto vazias mantendo a panela destampada ou tampada, como se pode ver na Figura 7. Ela mostra também o resultado da possível colocação de placas isolantes Silplate 1308 nas laterais das panelas através de simulações de aquecimento de uma panela sem isolante e outra com isolante.

Mesmo utilizando cálculos de transferência de calor em regime estacionário para a aplicação das cargas térmicas nas simulações computacionais os resultados obtidos foram próximos dos valores médios encontrados nas medições com pirômetro, com uma diferença de aproximadamente $10^{\circ} \mathrm{C}$.

As Figuras 7a e $7 \mathrm{~b}$ mostram respectivamente o perfil de temperatura do refratário de trabalho, na região da linha de escória, resultante do resfriamento transiente das panelas nas condições destampada e tampada após
20 minutos. Percebe-se que a panela que permaneceu destampada teve sua temperatura na face quente diminuída de $900^{\circ} \mathrm{C}$ para $754^{\circ} \mathrm{C}$, enquanto que para a tampada essa queda foi de $900^{\circ} \mathrm{C}$ para $793^{\circ}$. o perfil de temperatura da panela destampada foi mais linear do que para a tampada, fato facilmente percebido pelas temperaturas e pelo mapa de cores criado. As Figuras 7c e 7d mostram que os perfis de temperatura das panelas sem tampa e com tampa respectivamente se apresentam mais diferenciados após 40 minutos de resfriamento. Podemos ver que a panela que permanece destampada possuiu em sua face quente na linha de escória uma temperatura de $711,96^{\circ} \mathrm{C}$, já a panela tampada obteve uma temperatura de $770,57^{\circ} \mathrm{C}$. Pelo mapa de cores percebemos também que a panela destampada possui um perfil térmico mais linear do que o da panela tampada, o que comprova que a panela sendo tampada durante todo tempo de espera consegue manter uma maior energia calorífica interna. A figura 7e mostra o perfil de temperatura na linha de escória com a panela 

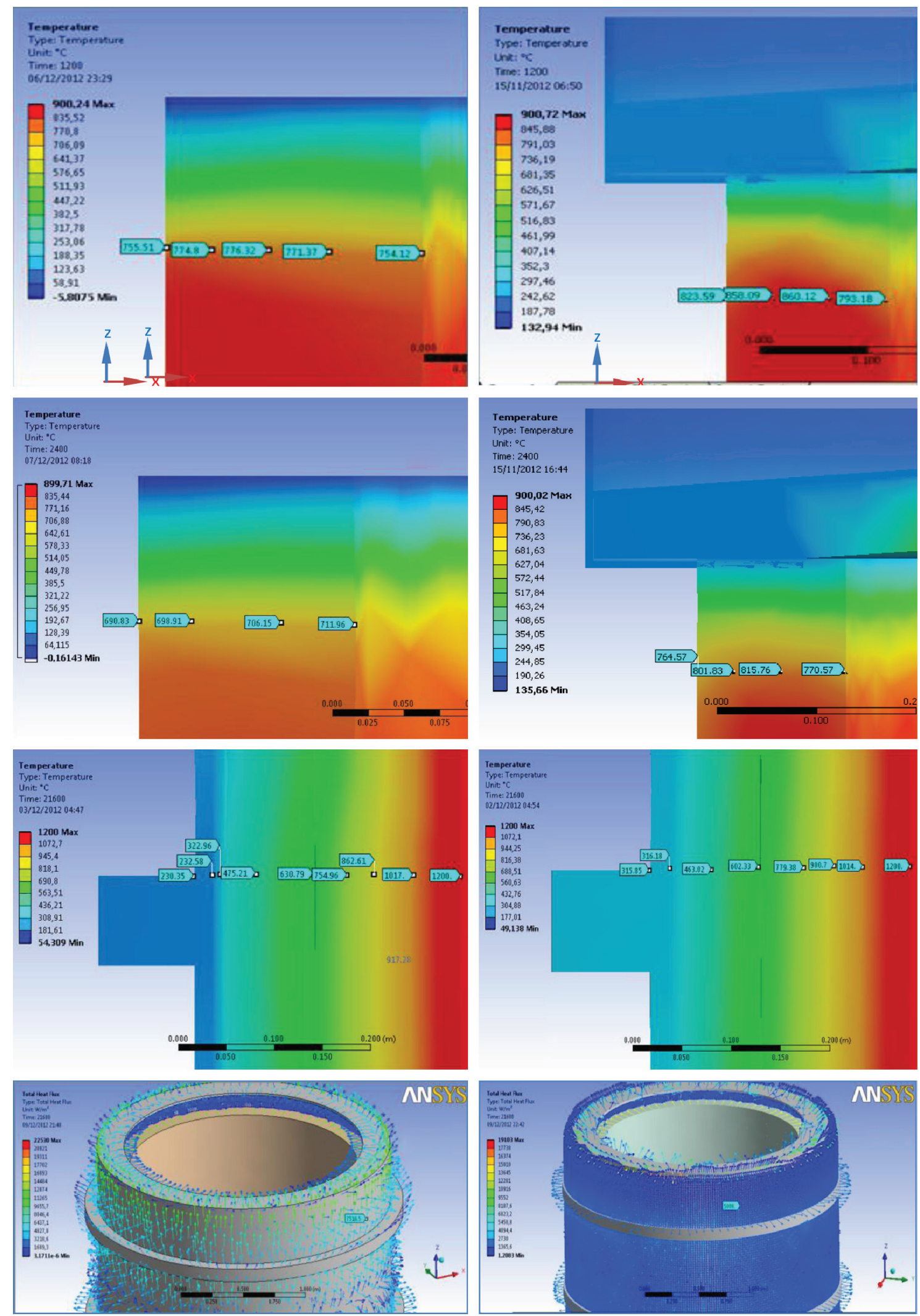

Figura 7. (a) e (b) perfil de temperatura no refratário de trabalho na LE para resfriamento sem tampa e com tampa após I.200 s respectivamente; (c) e (d) perfil de temperatura no refratário de trabalho na LE para resfriamento sem tampa e com tampa após $2.400 \mathrm{~s}$ respectivamente; (e) perfil de temperatura na LE após $21.600 \mathrm{~s}$ em aquecimento para panela normal; (f) perfil de temperatura na LE após $21.600 \mathrm{~s}$ em aquecimento para panela com isolante; ( $\mathrm{g}$ ) fluxo de calor na linha de escória em regime transiente $21.600 \mathrm{~s}$ para panela normal; (h) fluxo de calor na linha de escória em regime transiente $21.600 \mathrm{~s}$ para panela com isolante. 
sem isolante em uma simulação de aquecimento durante $21.600 \mathrm{~s}$ considerando que a face interna estivesse à uma temperatura constante de $1.200^{\circ} \mathrm{C}$. Assim, a carcaça metálica atingiu uma temperatura de $316^{\circ} \mathrm{C}$, enquanto que a panela com isolante térmico do tipo placa, nas mesmas condições de simulação, atingiu uma temperatura de $230^{\circ} \mathrm{C}$ como visto em $7 f$.

As Figuras $7 \mathrm{~g}$ e $7 \mathrm{~h}$ mostram o fluxo de calor nas mesmas condições citadas em 7 e e $7 f$ para a panela normal e com isolante. O fluxo de calor pela panela normal é maior e menos uniforme do que para a panela com isolante e que os valores de fluxo de calor na linha de escória são de $7.510 \mathrm{~W} / \mathrm{m}^{2}$ e $5.008 \mathrm{~W} / \mathrm{m}^{2}$ para as panelas sem isolante e com isolante respectivamente.

\section{CONCLUSÕES}

Os testes realizados com as panelas utilizando e não utilizando a tampa e usando a abobada do forno- panela determinaram as diferenças de taxas quedas de temperatura nas condições distintas. $\mathrm{O}$ uso da tampa faz com que a taxa de queda de temperatura diminua em média $47 \%$ nas perdas até a etapa de adição de areia de vedação e em média $45 \%$ até antes do vazamento. Os resultados mostraram que todas as panelas destampadas chegaram com temperaturas inferiores a ideal $\left(800^{\circ} \mathrm{C}\right)$ e aquelas que demoraram a ser tampadas obtiveram grandes quedas de temperatura.
O uso da abobada ajuda na diminuição da queda de temperatura no interior da panela, mas desde que a panela tenha sido previamente tampada. Com o uso da tampa e abóbada a taxa de queda de temperatura diminui em média $55 \%$. O uso conjunto das duas práticas só se mostra eficiente se não houver demora nos procedimentos experimentados.

A queda de temperatura do aço líquido existente no período entre o vazamento e a chegada da panela no forno-panela é influenciada pela temperatura interna da panela antes do vazamento sendo estes dois fatores inversamente proporcionais. Consequentemente a queda de temperatura do aço líquido influencia na energia elétrica consumida no forno-panela, sendo também estes dois fatores inversamente proporcionais.

Os resultados das simulações computacionais foram condizentes e aproximados com os dados colhidos na planta, e mostraram o perfil de temperatura esperado com ou sem a utilização da tampa. A colocação de placas isolantes diminui a perda de calor pelos refratários, evidenciado pelos valores e distribuição do fluxo de calor pela carcaça metálica, mantendo assim uma maior energia térmica dentro da panela por mais tempo.

\section{Agradecimentos} sita S.A.

\section{REFERÊNCIAS}

I Lopes HLP. Modelo para previsão da condição térmica de panelas de aciaria [dissertação de mestrado]. Belo Horizonte: Universidade Federal de Minas Gerais; 2007.

2 Minion RL, Leckie CF. Steel temperatura control in the ladle in a high productivity BOF shop. In: AIME. Proceeding of 69th Steelmaking Conference; 1986; Washington, USA. Englewood: AIME; 1986.

3 Ferreira NF. Controle da temperatura do aço líquido em uma aciaria elétrica [tese de doutorado]. Porto Alegre: Universidade Federal do Rio Grande do Sul; 2000.

4 Gupta N, Chandra S. Temperature prediction for controlling casting superheat temperature. ISIJ International. 2004;44(9):1517-1526. http://dx.doi.org/I0.2355/isijinternational.44.15I7

5 Fredman TP. Heat transfer in steelmaking ladle refractories and steel temperature. Scandinavian Journal of Metallurgy. 2000;29(6):232-258. http://dx.doi.org/I0.1034/j. I600-0692.2000.d0 I-28.x

6 Incropera FP, De Witt DP. Fundamentos de transferência de calor e de massa. 5. ed. Rio de Janeiro: LTC; 2003.

7 Seshadri V, Tavares RP, Silva CA, Silva IA. Fenômenos de transporte: fundamentos e aplicações nas engenharias metalúrgica e de materiais. São Paulo: Associação Brasileira de Metalurgia, Materiais e Mineração; 2010.

8 Suzaki K, Viana JF, Barbosa WF. Controle de temperatura nos processos de refino primário, refino secundário e lingotamento contínuo de aços: uma abordagem prática. In: Associação Brasileira de Metalurgia, Materiais e Mineração. 43 Seminário de Aciaria - Internacional; 2012; Belo Horizonte, Brasil. São Paulo: ABM; 20I2. p. 36-58.

9 Andrade HL, Stratton BA, Wheeler JG, Duarte JC, Nascimento RAD. O sistema de tampa de panela articulada da Stelco: uma tecnologia de alta eficiência energética. In: Associação Brasileira de Metalurgia, Materiais e Mineração. Anais do $31^{\circ}$ Seminário de Fusão, refino e solidificação dos metais; 2000; Vitória, Brasil. São Paulo: ABM; 2000.

Aceito: 19/9/2013

Recebido: 01/04/2014 